This item was submitted to Loughborough's Research Repository by the author.

Items in Figshare are protected by copyright, with all rights reserved, unless otherwise indicated.

\title{
Physico-chemical and dielectric parameters for the monitoring of carbon sequestration in basalt and silica media
}

PLEASE CITE THE PUBLISHED VERSION

https://doi.org/10.1016/j.eti.2020.101052

\section{PUBLISHER}

Elsevier

VERSION

AM (Accepted Manuscript)

\section{PUBLISHER STATEMENT}

This paper was accepted for publication in the journal Environmental Technology \& Innovation and the definitive published version is available at https://doi.org/10.1016/j.eti.2020.101052.

\section{LICENCE}

CC BY-NC-ND 4.0

\section{REPOSITORY RECORD}

Rabiu, KO, LK Abidoye, and Diganta Das. 2020. "Physico-chemical and Dielectric Parameters for the Monitoring of Carbon Sequestration in Basalt and Silica Media”. Loughborough University. https://hdl.handle.net/2134/12652499.v1. 


\title{
PHYSICO-CHEMICAL AND DIELECTRIC PARAMETERS FOR THE MONITORING OF CARBON SEQUESTRATION IN BASALT AND SILICA MEDIA
}

\author{
K. O. Rabiu' ${ }^{1,2}$, L. K. Abidoye ${ }^{1,2}$, and D. B. Das ${ }^{1, *}$
}

${ }^{1}$ Chemical Engineering Department, Loughborough University, Loughborough, Leicestershire, LE11 3TU United Kingdom

${ }^{2}$ Current address: Civil Engineering Department, Osun State University, Osogbo, Nigeria

${ }^{*}$ Corresponding Author (E-mail: d.b.das@lboro.ac.uk)

\begin{abstract}
Currently, there are concerns about the safety of carbon sequestration in the geological media. To assuage this concern, scientists and engineers have the tasks to demonstrate fool-proof and comprehensive techniques that can monitor the movement, or otherwise, concentration of the injected $\mathrm{CO}_{2}$ in the subsurface. In this work, well-defined laboratory experiments were used to demonstrate the key physico-chemical characteristics and dielectric parameters that are useful in monitoring carbon sequestration sites. The porous materials used were basalt and silica sand samples to demonstrate the possibility of $\mathrm{CO}_{2}$ injection into different media. To simulate the resident fluids, distilled and brine water samples were used in separate experimentations. Also, the pressures and temperatures were chosen to correspond to different geological depths which are relevant for $\mathrm{CO}_{2}$ injection. The $\mathrm{pH}$, bulk electrical conductivity $\left(\sigma_{\mathrm{b}}\right)$ and bulk dielectric permittivity $\left(\varepsilon_{\mathrm{b}}\right)$ of the system were measured for the two different media. On one hand, the decrease in $\mathrm{pH}$ was clearly observed in both the basalt and silica sand after the exposure to $\mathrm{CO}_{2}$. On the other hand, $\sigma_{\mathrm{b}}$ and $\varepsilon_{\mathrm{b}}$ increased as $\mathrm{CO}_{2}$ was injected. Our results further revealed a higher ion mobilization potential in basalt medium than that in silica sand. This results in lower $\mathrm{pH}$ and higher electrical conductivity in the basalt medium than the silica medium. Thus, a simultaneous measurement of $\mathrm{pH}, \sigma_{\mathrm{b}}$ and $\varepsilon_{\mathrm{b}}$ are proposed as a multiparameter approach to monitor $\mathrm{CO}_{2}$ leakage from the storage reservoir. As far as we are aware, this is the first work in the open literature that reports simultaneous dielectric and electrical behaviours of $\mathrm{CO}_{2}$-water-porous media system for basalt porous medium in connection with carbon sequestration.
\end{abstract}

Keywords: Basalt; silica; shallow aquifer; distilled water; brine; $\mathrm{pH}$; bulk electrical conductivity $\left(\sigma_{\mathrm{b}}\right)$; bulk dielectric permittivity $\left(\varepsilon_{\mathrm{b}}\right)$

\section{Introduction}

Carbon capture and sequestration (CCS) is a promising approach for reducing atmospheric $\mathrm{CO}_{2}$ emission (Abidoye and Das, 2020; Kim et al., 2018; Terzi et al., 2014). The process starts with the capture of $\mathrm{CO}_{2}$ primarily from power plants, transport through pipeline or ships and injection into a geological formation (Rabiu et al., 2017b; Myer, 2011). Subsurface formations such as depleted hydrocarbon fields (Adebayo et al., 2017; Cao et al., 2020), saline aquifers (Borner and Spitzer, 2019), basalts (Snaebjornsdottir et al., 2020) and un-mineable coal seams (Talapatra, 2020) have been identified to be suitable as $\mathrm{CO}_{2}$ repositories (Metz et al., 2005; Cao et al., 2020). In particular, saline aquifers have been suggested to provide an enormous potential of $\mathrm{CO}_{2}$ storage capacity when compared with the other geological formations (Metz et al., 2005; Snaebjornsdottir et al., 2020). On the other hand, depleted oil and gas reservoirs can provide both economic and $\mathrm{CO}_{2}$ storage advantages. Basalt repositories are now gaining popularity as the site for $\mathrm{CO}_{2}$ sequestration because they have the potential to store $\mathrm{CO}_{2}$ permanently without any risk of leakages after storage.

The major trapping mechanisms that take place during $\mathrm{CO}_{2}$ sequestration in saline aquifers are structural, residual, solubility and mineral trapping (Rabiu et al., 2017a; Metz et al., 2015). Previous studies have shown that salinity has a significant influence on $\mathrm{CO}_{2}$ trapping mechanisms (AlKhdheeawi et al., 2017; Kumar et al., 2020). For example, lower salinity enhances residual and solubility trapping significantly and prevents the free mobility of $\mathrm{CO}_{2}$ in the aquifer. Salinity is less 
important in basalt rock but, its consideration is essential in saline aquifers typically composed of silica sand. Injection of $\mathrm{CO}_{2}$ into saline aquifer has been considered as a two-phase flow process because the injected $\mathrm{CO}_{2}$ (non-wetting phase) displaces the resident brine water (wetting phase) during the drainage process (Abidoye and Das, 2020; Ajayi et al., 2019; Cao et al., 2020). On the other hand, when the injection of $\mathrm{CO}_{2}$ stops, the resident brine water (wetting phase) tends to displace the $\mathrm{CO}_{2}$ (non-wetting phase) during an imbibition process (Ajayi et al., 2019; Cao et al., 2020). These flow processes are expected to occur in presence of some geochemical reactions, for instance, reactions between water, $\mathrm{CO}_{2}$ and silica/basalt minerals can lower the $\mathrm{pH}$ (Little and Jackson, 2010). The reactions can buffer the fluid $\mathrm{pH}$ and increase alkalinity (Snaebjornsdottir et al., 2020; Kampman et al., 2014) which have a direct effect on dielectric properties of the media. The effect of rock-fluid reactions/interactions on $\mathrm{CO}_{2}$ solubility which affect the storage capacity of $\mathrm{CO}_{2}$ sequestration in saline aquifers have been studied by Emami-Meybodi et al. (2015) and Erfani et al. (2020). Emami-Meybodi et al. (2015) have reported a feasibility for enhancing $\mathrm{CO}_{2}$ dissolution by using a method that relies on injecting water on top of $\mathrm{CO}_{2}$ plume. Due to the geochemical reactions of $\mathrm{CO}_{2}$ and brine with the resident minerals, the $\mathrm{pH}$ and ion concentration of the brine change in the reservoir, and hence, the dielectric properties of the reservoir. Erfani et al. (2020) have studied the spatial and temporal dependency of such geochemical effects during $\mathrm{CO}_{2}$ sequestration in geological formations.

Generally, $\mathrm{CO}_{2}$ is injected as a supercritical fluid (i.e., pressure above 73 bar and temperature above $31.1^{\circ} \mathrm{C}$ ) and at the depth of $800 \mathrm{~m}$ or below (Rabiu et al., 2017a; Abidoye et al., 2014; Holloway, 2007; Metz et al., 2005). Supercritical $\mathrm{CO}_{2}$ is denser than gaseous $\mathrm{CO}_{2}$ but has lower density than the brine in the porous media (Rabiu et al., 2017a; Metz et al., 2005; Abidoye et al., 2014). Thus, after a $\mathrm{CO}_{2}$ injection cycle stops, the supercritical $\mathrm{CO}_{2}$ tends to move up to the confining layer due to the buoyancy force, i.e., the difference in densities between the injected $\mathrm{CO}_{2}$ and the resident brine (Altman et al., 2014; Ajayi et al., 2019; Khudaida and Das, 2014; Suekane et al., 2008; Cao et al., 2020). It is therefore important to ensure that the caprock in any CCS site is fully characterised to determine if there is any fault or fracture that might make the $\mathrm{CO}_{2}$ storage ineffective. Appropriate $\mathrm{pH}$ sensors can be used as an indicator to detect the leakage of $\mathrm{CO}_{2}$ (Blackford et al., 2020).

While the CCS is a feasible option to mitigate the problem of $\mathrm{CO}_{2}$ emission, the interplays of different parameters during $\mathrm{CO}_{2}$ injection are still not fully understood. This is because a number of parameters such as $\mathrm{CO}_{2}$ injection pressure, temperature and brine salinity govern the behaviour of $\mathrm{CO}_{2}$ spread and mixing in the subsurface. Also, some studies argue that an increase in the reservoir pressure during the $\mathrm{CO}_{2}$ injection will trigger earthquakes and consequently create faults or micro-fractures within the geological formation, which can eventually lead to $\mathrm{CO}_{2}$ leakage (Szulczewski, 2013; Rabiu et al., 2017a). The faulty caprock will allow the leakage of $\mathrm{CO}_{2}$ through the surface and subsurface where the potable drinking water is overlaid. This can result in the groundwater being contaminated and becoming more acidic, and therefore threatening the ecological system (Gupta and Yadav, 2020). Therefore, accurate monitoring of $\mathrm{CO}_{2}$ concentration during and after a CCS project is paramount for an efficient and effective CCS project.

Seismic methods have been used for monitoring of $\mathrm{CO}_{2}$ in the subsurface, but they are costly, and can usually quantify a limited range of $\mathrm{CO}_{2}$ saturations accurately (Ajayi et al., 2019; Furre et al., 2017). Electrical and electromagnetic methods, e.g., electrical resistivity tomography (ERT), electromagnetic resistivity (ER), geoelectrical method (GM), electromagnetic induction tomography (EMIT), are other important approaches that may be used for the quantification of $\mathrm{CO}_{2}$ saturation (Dafflon et al., 2012; Rabiu et al., 2017b; Ajayi et al., 2019). Wan et al. (2018) earlier examined the feasibility of permanent gravity gradiometry monitoring of geological $\mathrm{CO}_{2}$ storage using a method involving both surface and borehole measurements. Yang et al (2019) evaluated four surface-based geophysical methods for monitoring brine and $\mathrm{CO}_{2}$ leakage in sources of underground drinking water overlying a CCS site, and they concluded that it was important to combine downhole measurements with geophysical methods that can monitor both $\mathrm{CO}_{2}$ concentrations and total dissolved solids (TDS) to improve $\mathrm{CO}_{2}$ leak detection. Song et al. (2020) reported the application of an artificial neural network (ANN) in predicting the efficiency and effectiveness of $\mathrm{CO}_{2}$ trapping mechanisms in geological carbon sequestration and concluded that ANN model is an important tool for predicting the 
effectiveness of $\mathrm{CO}_{2}$ storage in a site. ANN model such as the one reported by Song et al (2020) is expected to be useful in the analysis of the monitoring data from existing CCS sites.

It can be assumed that the $\mathrm{CO}_{2}$ storage site selected for any CCS process is free from any potential leakage of $\mathrm{CO}_{2}$ after proper characterisation. However, monitoring the site is still required for the reliability of the process as well as regulatory purposes (White et al., 2020). As shown in Figure 1, potable water aquifer is situated above the sediment. The leaked $\mathrm{CO}_{2}$ follows a pathway (fractured caprocks) to reach the potable water aquifer and consequently contaminates it. Therefore, in this study, a portable and reliable early warning monitoring method (EWMM) for key parameters are conceptualised to characterise the potable groundwater contaminated by $\mathrm{CO}_{2}$. The methods and parameters were chosen in a way so as to promote straightforward techniques that would lead to the safety of geological sequestration site by engendering early warning in the case of $\mathrm{CO}_{2}$ leakage. These methods or techniques include dielectric permittivity, electrical conductivity and $\mathrm{pH}$ of the $\mathrm{CO}_{2-}$ water-porous media system.

By characterising the multiphase system $\left(\mathrm{CO}_{2}\right.$-water-porous media system), the changes in values of the dielectric permittivity, electrical conductivity as well as the $\mathrm{pH}$ with time, temperature, pressure and brine/water system will be recorded simultaneously and continuously. The trends observed in these parameters will serve to programme an automated alarm system. In case of any $\mathrm{CO}_{2}$ leakage, a signal will be sent to the sound alarm system and, this alerts the control/monitoring personnel to assess the situation and take appropriate measures. To further simplify the task of the measurements, time-domain reflectometry (TDR) was used to simultaneously measure the bulk dielectric permittivity and electrical conductivity of $\mathrm{CO}_{2}$-water-porous media system. This approach confers additional assurance on the monitoring signals from sequestration system. It also eliminates any time lag between the two parameters. The other parameter, $\mathrm{pH}$, was measured by stand-alone $\mathrm{pH}$ sensor, by taking fluid samples before and after the experiment.

A previous study (Abidoye and Das, 2015b) investigates the monitoring of $\mathrm{CO}_{2}$ leakage using dielectric properties, $\mathrm{pH}$ and membrane, but their work is limited to the effects of different depths. Similarly, Lamert et al. (2012) and Kharaka et al. (2010) investigate the changes in the potable groundwater chemistry after contamination with $\mathrm{CO}_{2}$. They conclude that the dissolution of $\mathrm{CO}_{2}$ in the groundwater reduces the $\mathrm{pH}$ and become toxic, which will have negative implications on the aquatic animals. Bosch et al. (2016) and Borner et al. (2017) analyse geoelectrical properties of $\mathrm{CO}_{2}$-brinerock interaction to detect any possible $\mathrm{CO}_{2}$ leakage. Also, Falcon-Suarez et al. (2017) develop a multiparameter, thermo-hydro-mechanical-chemical database required to validate monitoring tools and simulators for prediction of geo-mechanical properties of $\mathrm{CO}_{2}$ sequestration reservoirs. However, sufficient number of studies that deal with monitoring the leakage of $\mathrm{CO}_{2}$ in various groundwater types (e.g., distilled water, tap water, $\mathrm{MgCl}$ brine water and $\mathrm{NaCl}$ brine water) that can provide a broad understanding of the relevant issues are still lacking, particularly since different groundwater types contain various constituents of ions and minerals. Also, the porous materials used in the present study are basalt and silica sand.

In addressing the above points, well-defined laboratory experiments (static flow conditions) were used to identify the significance of the physico-chemical characteristics and dielectric parameters that are useful in monitoring carbon sequestration sites with particular reference to sites containing silica and basalt medium. 


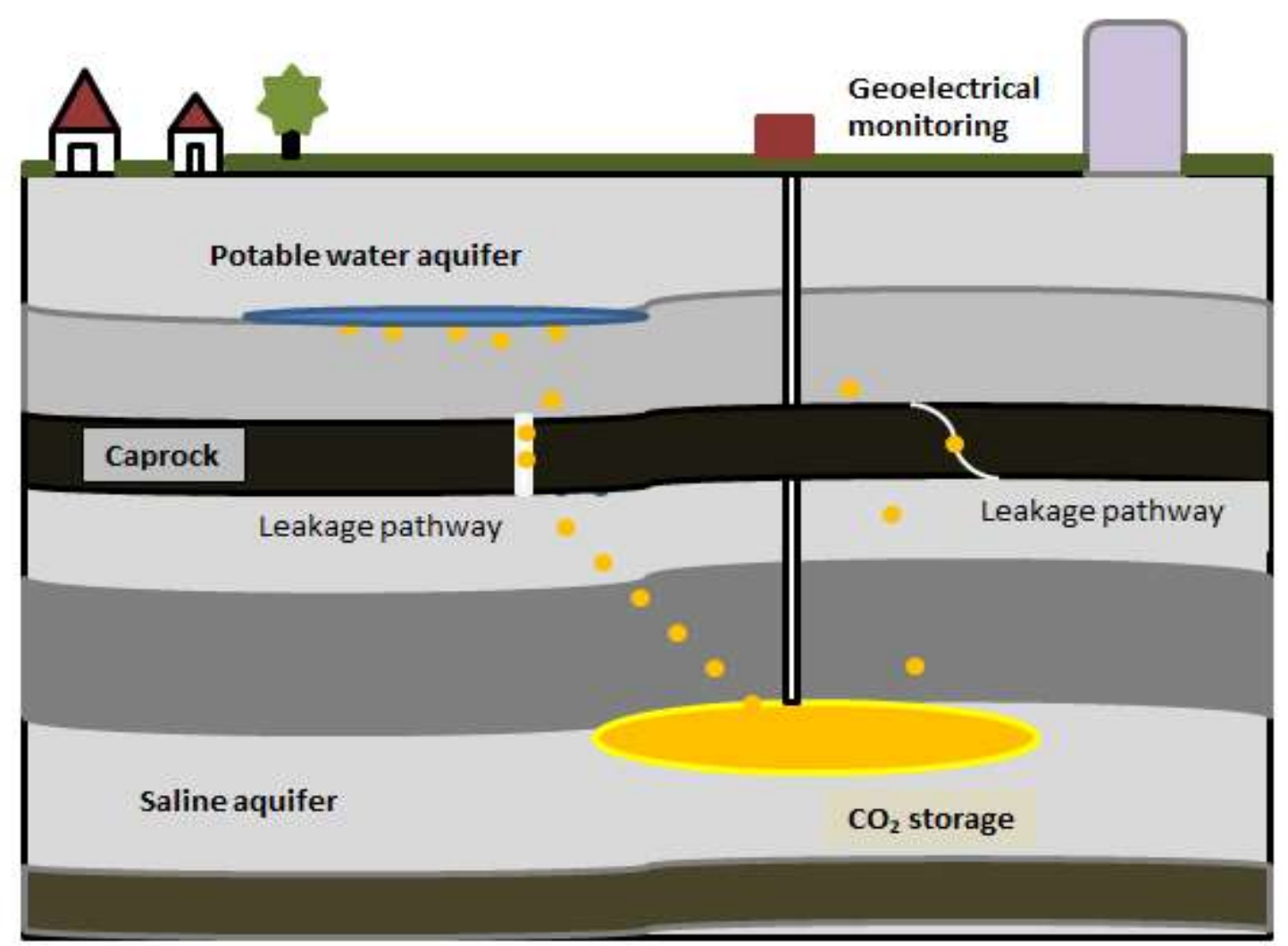

Figure 1 Schematic diagram of $\mathrm{CO}_{2}$ leakage into potable groundwater aquifer

\section{Methodology}

The laboratory experiment was designed to monitor the presence of $\mathrm{CO}_{2}$ in porous media saturated with distilled, tap and brine water. The porous materials used are silica and basalt sand and the characteristics of the samples used are described in Table 1. The time-domain reflectometry (TDR) probe was prepared in-house (Abidoye and Das 2015a; Rabiu et al., 2017b) and used to measure both bulk dielectric permittivity and bulk electrical conductivity simultaneously. In-situ measurement of the bulk electrical conductivity and bulk dielectric constant data acquired by the TDR were automatically transferred to the data acquisition system (CR10X datalogger, Campbell Scientific Ltd, Shepshed, UK). The $\mathrm{pH}$ measurements were done using a digital $\mathrm{pH}$ meter (Fisher Scientific, Loughborough, UK). The $\mathrm{pH}$ was calibrated before each experiment. The $\mathrm{pH}$ measurement of the water sample was taken before the injection of $\mathrm{CO}_{2}$ and at the end of the experiment when the $\mathrm{CO}_{2}$ had already dissolved in the water.

\subsection{Materials and Methods}

This work investigated two unconsolidated sand samples, silica sand (Minerals Marketing Company, Cheshire, UK) and basalt sand (Aqua Maniac, Delaware, USA). The physical properties such as porosity and average particle size of each mentioned porous materials were determined experimentally which are listed in Table 1 . The porosity of the sand material was determined by packing porous material (Basalt/silica sand) into a cylinder of known volume and saturating the bed with a measured amount of water. The porosity was then calculated using the Equation 1.

$\emptyset=\frac{\mathrm{R}_{\mathrm{t}}-\mathrm{R}_{\mathrm{s}}}{\mathrm{R}_{\mathrm{t}}}=\frac{\mathrm{R}_{\mathrm{v}}}{\mathrm{R}_{\mathrm{t}}}=\frac{\mathrm{R}_{\mathrm{w}}}{\mathrm{R}_{\mathrm{t}}}$

where $\emptyset$ is porosity, $R_{t}$ is the total volume of a porous media sample, $R_{s}$ is the volume of solids in the sample, $R_{v}$ is the volume of openings (voids), and $R_{w}$ is the volume of water that will occupy the voids space. Before the porosity experiment, the silica sand and basalt were washed with distilled water and dried to remove any clay content. Moreover, SEM (Zeiss 1530VP) images were taken before the experiment to examine surface morphology and roughness of the particles which make up the porous 
materials used. As shown in Figure 2, basalt sand particles have a hexagonal shape while silica sand particles are more angular.

Table 1 Characteristics of the porous materials used in the experiments

\begin{tabular}{|lcc|}
\hline Parameters & Silica Sand & Basalt Sand \\
\hline Porosity $(\%)$ & $39 \pm 0.25$ & $42 \pm 0.30$ \\
\hline Average particle size $(\mu \mathrm{m})$ & $968 \pm 253$ & $1016 \pm 296$ \\
\hline
\end{tabular}

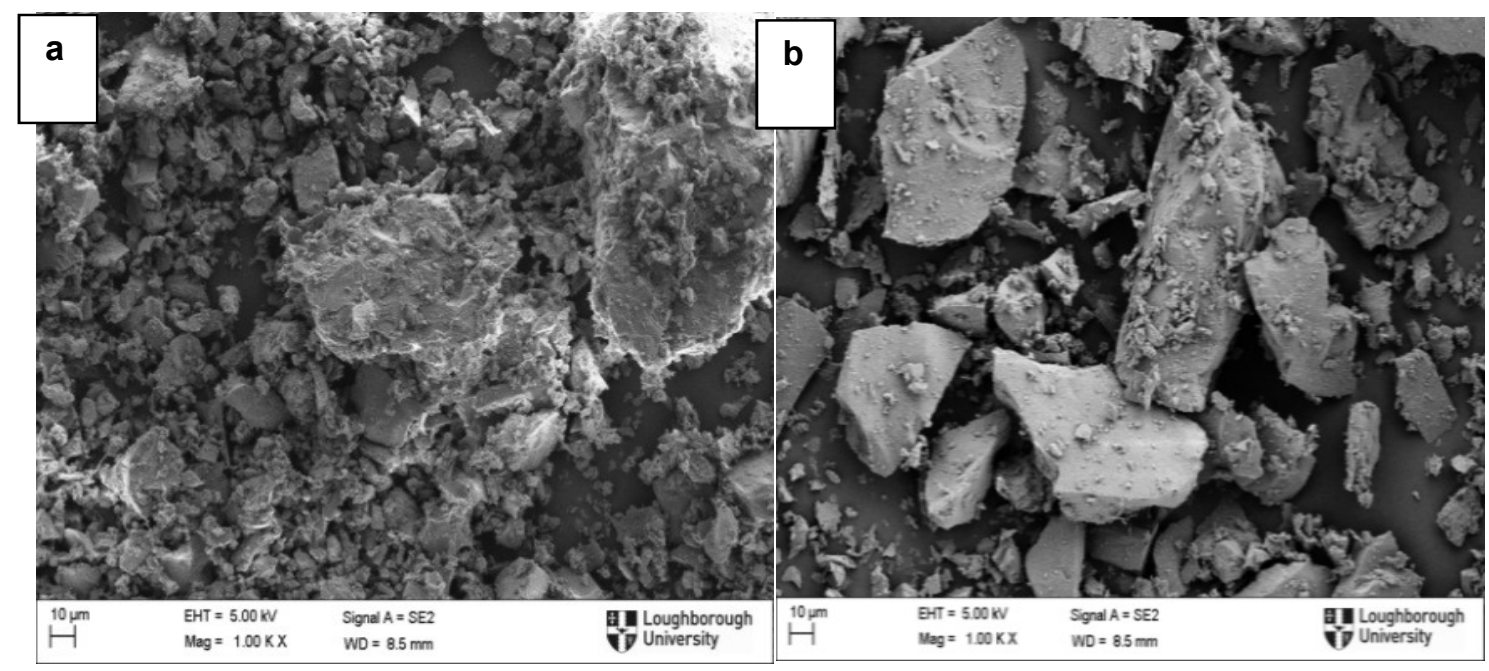

Figure 2 Scanning electron microscope (SEM) images of: (a) basalt and (b) silica sand particles.

\subsection{Experimental Methods and Procedures}

The stainless-steel sample holder used in the experiment was fabricated in-house in the workshop at Loughborough University. It had dimensions of $4 \mathrm{~cm}$ in height and $10 \mathrm{~cm}$ in diameter. The simulated water used in the experiment was either distilled or brine water. The brine water was prepared in the laboratory by adding sodium chloride or magnesium chloride salts to the distilled water. The sodium chloride and magnesium chloride salts were purchased from Fisher Scientific, Loughborough (UK).

To start the experiment, $500 \mathrm{~g}$ of the sand particles (silica or basalt) were deposited into the sample holder and saturated with distilled or brine water. It was then covered by the stainless-steel top end piece and all the joint bolts were firmly tightened to avoid any leakage of the $\mathrm{CO}_{2}$ during the experiment. Before $\mathrm{CO}_{2}$ injection started, the samples of the brine and distilled water were collected from saturated porous media and measured with the $\mathrm{pH}$ probe/meter. The $\mathrm{pH}$ probe/meter was purchased from Fisher Scientific (Loughborough, UK). The $\mathrm{CO}_{2}$ gas $(99.9 \%$ purity) used in this work was procured from BOC gases (Leicester, UK).

The $\mathrm{ScCO}_{2}$ fluid pump (Teledyne Isco, Lincoln NE) was filled with $\mathrm{CO}_{2}$ from the $\mathrm{CO}_{2}$ cylinder by opening valve 1 (V-1; Figure 3). Thereafter, $\mathrm{V}-1$ was closed and the $\mathrm{ScCO}_{2}$ fluid pump was set to the experimental pressure. The heater was switched on and also set at the experimental temperature. When temperature and pressure reached the predetermined values, i.e., when there was equilibrium in experimental conditions (both temperature and pressure), V-3 was opened (see Figure 3 ) and the $\mathrm{CO}_{2}$ was injected. This work simulated static potable groundwater that is not moving or moving very slowly. Therefore, the experiment was carried out in static conditions (i.e., $\mathrm{CO}_{2}$ was accumulated or dissolved in water). Some experiments were carried out for short periods of time while others were left for longer periods of time. The in-situ electrical properties were measured automatically by data logger, and the data were collected by personal computer (see, e.g., Figure 3). The pH probe/meter measured the water sample before and after the experiments. It is very important to carry out 
a calibration prior to making each measurement in order to assure that the reading which is given by the $\mathrm{pH}$ meter is accurate.

\subsection{Design of the experimental conditions}

The experiments were designed so as to simulate the conditions that are encountered during the leakage of $\mathrm{CO}_{2}$ from a geological sequestration site in the shallow subsurface, i.e., temperature, pressure and salinity that are relevant to potable shallow aquifers. It can be recalled that the leakage of $\mathrm{CO}_{2}$ from storage aquifers into shallow aquifers can lower the $\mathrm{pH}$ of the groundwater and make it to become more acidic, which will have a negative impact on the aquatic animals.

This study developed an innovative method of monitoring the behaviour of the contaminant $\mathrm{CO}_{2}$ in the groundwater aquifers. The geological conditions were defined using the reports of the Abidoye and Das (2015a) and the modified conditions were listed in Table 2.

On one hand, the in-situ measurements of the electrical parameters (i.e., bulk dielectric permittivity $\left(\varepsilon_{\mathrm{b}}\right)$ and the bulk electrical conductivity $\left(\sigma_{\mathrm{b}}\right)$ ) were measured simultaneously; and on the other hand, the water samples were collected before and after the experiment for the $\mathrm{pH}$ measurements. Figure 3 shows the schematic diagram of the $\mathrm{CO}_{2}$ leakage into the potable groundwater aquifer.

The soil electrical properties and water saturation determine the amount of $\mathrm{CO}_{2} / \mathrm{brine}$ in reservoirs. The electrical properties is often modelled empirically using the Archie's law (Archie, 1942); however, the relation is known to be limited in its applicability as it works best when the pore water conductivity does not change (Borner et al. 2013). The law is purely an empirical law and attempts to quantify ion transport in clean and consolidated sand. For example, we can consider Jin and Yang (2020) who have attempted a theoretical and experimental quantification of the relationship between electrical resistivity and hydrate saturation in sand material. The author concluded that the ERTs are in better agreement with the experimental measurements, while the Archie's law introduced a larger error at higher hydrate saturation. We have used Archie's law in our past work where the experimental conditions are within the range of applicability of the law (Abidoye and Das, 2015a); however, in this work, the pore water conductivity is expected to change at the pore-scale, particularly in basalt media. Furthermore, we use unconsolidated porous domain with a view to identify the key physico-chemical and dielectric characteristics. Considering the above points, this work does not attempt to use Archie's law to fit the data obtained in this work.

\section{$2.4 \mathrm{pH}$ Measurement}

The $\mathrm{pH}$ of the solution was measured using the Hydrus $500 \mathrm{pH}$ meter (Fisher Scientific, Loughborough, UK). The water sample was collected before and after the experiment for the $\mathrm{pH}$ measurement. The $\mathrm{pH}$ meter was calibrated after each experiment to ensure consistent results.

\subsection{Time-domain reflectometry (TDR)}

The TDR probes used in this work were fabricated in the workshop (Loughborough University, UK) (Abidoye and Das 2015a; Rabiu et al., 2017b). The electrical pulses were generated by the TDR100. These pulses travelled through the coaxial cables that were connected to the TDR probes. The working procedure of the TDR probe can be found in the work of Rabiu et al. (2017b). The TDR measures both the bulk dielectric permittivity and bulk electrical conductivity simultaneously.

Recently, Rabiu et al. (2017b) and Abidoye and Das (2015a) carried out investigations on the effects of flow experiments on the electrical properties and water saturation relationships using locallyfabricated TDR. Some parameters such as pressure, temperature and salinity were shown to influence the dielectric and water saturation relationships during the flow experiments. On the other hand, $\mathrm{pH}$, flow rate and salt types were concluded to show no significant effect (Rabiu et al., 2017b; Abidoye and Das, 2015a). The current work investigates the dielectric and physico-chemical monitoring of the dissolution of $\mathrm{CO}_{2}$ in water (i.e., brine, distilled, tap) during a static experiment. 


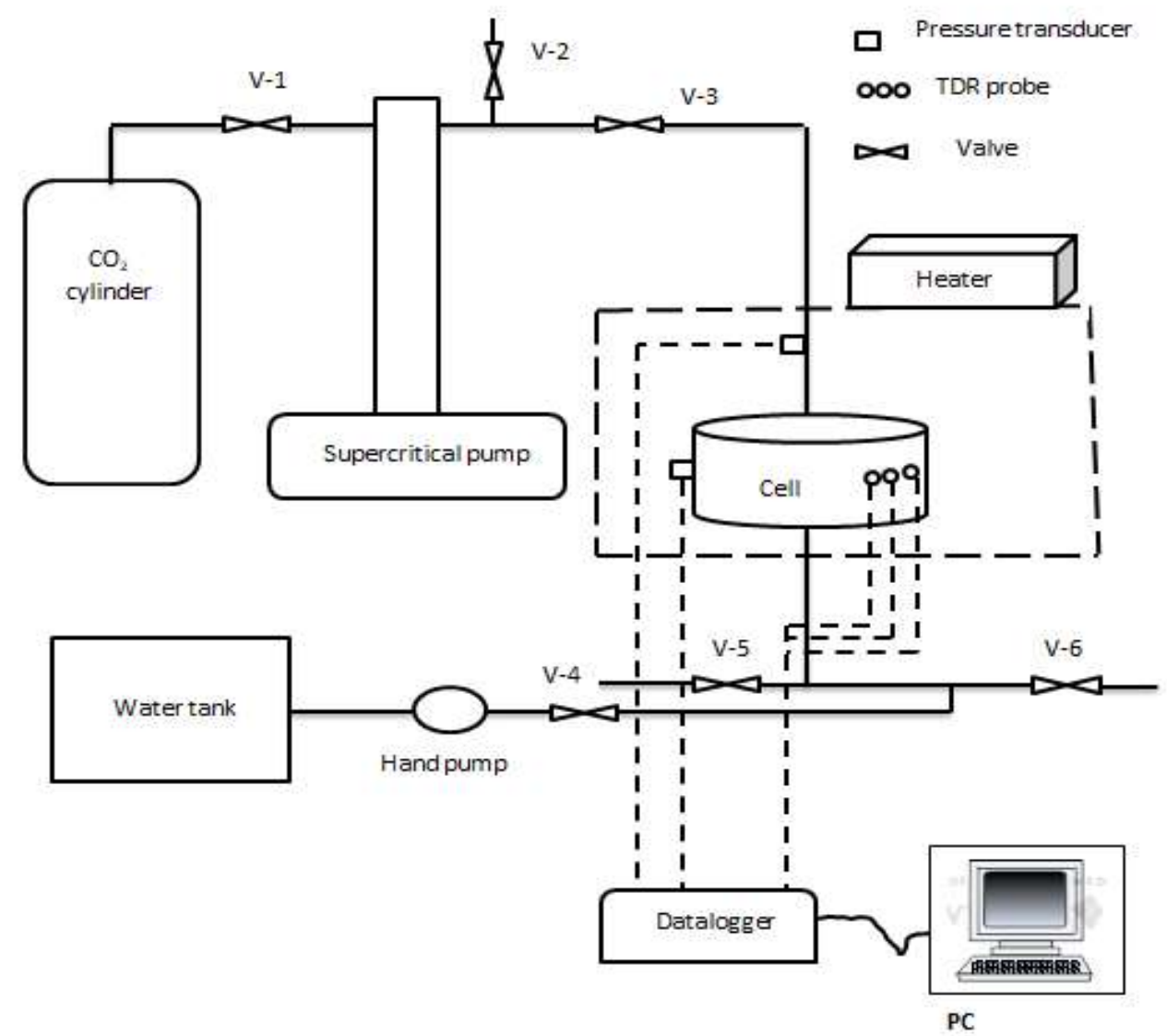

Figure 3 A schematic diagram of the static experimental system (adapted from Rabiu et al., 2017b).

Table 2 List of experimental conditions simulated in this work (the geothermal gradients were determined using the reports of Abidoye and Das (2015b))

\begin{tabular}{|c|c|c|c|c|c|c|c|}
\hline Exp. & $\begin{array}{l}\text { Porous } \\
\text { Media }\end{array}$ & $\begin{array}{l}\text { Simulated } \\
\text { Aquifer } \\
\text { groundwater }\end{array}$ & $\begin{array}{l}\text { Depth } \\
\text { (m) }\end{array}$ & $\begin{array}{c}\text { Temperature } \\
\left({ }^{\circ} \mathrm{C}\right)\end{array}$ & $\begin{array}{l}\text { Pressure } \\
\text { (bar) }\end{array}$ & $\begin{array}{c}\text { Injection } \\
\text { duration } \\
\text { (min) }\end{array}$ & $\begin{array}{c}\mathrm{CO}_{2} \\
\text { Phase }\end{array}$ \\
\hline 1 & Basalt sand & $\begin{array}{l}\text { Distilled } \\
\text { water }\end{array}$ & 200 & 31 & 54 & 30 & Gas \\
\hline 2 & Silica sand & $\begin{array}{l}\text { Distilled } \\
\text { water }\end{array}$ & 200 & 31 & 54 & 30 & Gas \\
\hline 3 & Basalt sand & Brine water & 200 & 31 & 54 & 30 & Gas \\
\hline 4 & Silica sand & Brine water & 200 & 31 & 54 & 30 & Gas \\
\hline 5 & Silica sand & $\begin{array}{l}\text { Distilled } \\
\text { water }\end{array}$ & 100 & 25 & 27 & 360 & Gas \\
\hline 6 & Silica sand & Tap water & 100 & 25 & 27 & 360 & Gas \\
\hline 7 & - & Tap water & 100 & 25 & 27 & 360 & Gas \\
\hline 8 & - & $\begin{array}{l}\text { Distilled } \\
\text { water }\end{array}$ & 100 & 25 & 27 & 360 & Gas \\
\hline
\end{tabular}


264

\section{$3.1 \mathrm{pH}$ Analysis}

The chemical composition of the experimental potable groundwater conducted in this study was significantly affected by $\mathrm{CO}_{2}$ exposure. The results of the $\mathrm{pH}$ analyses before and after the experiments are reported in Table 3 . As the table shows, there is a significant $\mathrm{pH}$ drop in the distilled water + basalt $+\mathrm{CO}_{2}$-reacted solution (i.e. from $8.41 \pm 0.09$ to $6.47 \pm 0.12$ ) after short-term $\mathrm{CO}_{2}$ injection. However, there is a lesser degree of fall in the $\mathrm{pH}$ for the distilled water + silica sand $+\mathrm{CO}_{2-}$ reacted solution (i.e., from $6.12 \pm 0.07$ to $5.65 \pm 0.10$ ). The observed reduction in the $\mathrm{pH}$ values can be attributed to the dissolution of injected $\mathrm{CO}_{2}$ in distilled water which resulted in an acidic medium, i.e., formation of carbonic acid in the porous medium as shown in equation (2).

$\mathrm{CO}_{2}+\mathrm{H}_{2} \mathrm{O} \leftrightarrow \mathrm{H}_{2} \mathrm{CO}_{3} \leftrightarrow \mathrm{H}^{+}+\mathrm{HCO}_{3}^{-}$

As expected, this $\mathrm{pH}$ reduction in the $\mathrm{CO}_{2}-\mathrm{H}_{2} \mathrm{O}$-sand systems confirms the reactive nature of the injected $\mathrm{CO}_{2}$ (Terzi et al., 2014; Rabiu et al., 2017a). There was more significant drop in $\mathrm{pH}$ when $\mathrm{CO}_{2}$ reacted with water in the basalt sand medium than in water-silica sand medium. This can be attributed to the presence of some minerals such as magnesium, iron and aluminium in the basalt sand (Metz et al., 2005; Petrik and Mabee, 2005). The quantities of these minerals are lower in silica sand (see Figures A1, A2 at the appendix). Studies have shown that basalt rocks are suitable for permanent sequestration of $\mathrm{CO}_{2}$ but their conversion into solid carbonates are very slow (Rabiu et al., 2017a,b; Saebjornsdottir et al., 2020). In order to minimise the leakage of $\mathrm{CO}_{2}$ into potable groundwater, basalt medium offers more promise than silica sand medium.

Table 3 Changes in $\mathrm{pH}$ of water-saturated basalt and silica porous media before and after $\mathrm{CO}_{2}$ injection for short experiment (30 minutes)

\begin{tabular}{|c|c|c|c|c|c|}
\hline $\begin{array}{c}\text { Simulated } \\
\text { Potable } \\
\text { Aquifer }\end{array}$ & $\begin{array}{c}\text { Depth } \\
(\mathrm{m})\end{array}$ & $\begin{array}{c}\mathrm{pH} \text { before } \mathrm{CO}_{2} \\
\text { injection in the } \\
\text { saturated silica } \\
\text { sand }\end{array}$ & $\begin{array}{c}\mathrm{pH} \text { after } \mathrm{CO}_{2} \\
\text { injection in the } \\
\text { saturated silica } \\
\text { sand }\end{array}$ & $\begin{array}{c}\mathrm{pH} \text { before } \mathrm{CO}_{2} \\
\text { injection in the } \\
\text { saturated basalt } \\
\text { sand }\end{array}$ & $\begin{array}{c}\mathrm{pH} \text { after } \mathrm{CO}_{2} \\
\text { injection in the } \\
\text { saturated basalt } \\
\text { sand }\end{array}$ \\
\hline $\begin{array}{c}\text { Distilled } \\
\text { water }\end{array}$ & 200 & $6.12 \pm 0.07$ & $5.65 \pm 0.10$ & $8.41 \pm 0.09$ & $6.47 \pm 0.12$ \\
\hline Brine water & 200 & $5.79 \pm 0.10$ & $5.55 \pm 0.09$ & $7.40 \pm 0.08$ & $5.97 \pm 0.10$ \\
\hline
\end{tabular}

\subsection{Electrical Conductivity and Dielectric Permittivity}

One of the environmental issues of the $\mathrm{CO}_{2}$ sequestration process is the potential leakage of the $\mathrm{CO}_{2}$ from the storage reservoirs into the fresh groundwater aquifers. This consequently contaminates the potable water and makes it a threat to aquatic animals and living organisms. The characteristics of the water-saturated porous material when contaminated by $\mathrm{CO}_{2}$ are expected to be different for various types of aquifers. For example, the characteristics in $\mathrm{CO}_{2}-\mathrm{H}_{2} \mathrm{O}$-basalt sand will be different from $\mathrm{CO}_{2}-$ $\mathrm{H}_{2} \mathrm{O}$-silica sand. This can be attributed to the presence of different mineral constituents in various water samples. Work on the static experiment on the monitoring of dielectric properties of $\mathrm{CO}_{2}$-waterlimestone/silica sand has been studied for different geological depths (Abidoye and Das, 2015a) and the authors have concluded that different depths have different effects on the dielectric properties.

In the present study, the results of the investigation of the scenarios in which the dielectric characterisation was used to monitor the potable groundwater contaminated by leaked $\mathrm{CO}_{2}$ are presented. The effect of different types of potable groundwater on the dielectric properties was examined. This work simulated four distinct fluids in analogy to the common mixtures of fluids or solutions found in groundwater aquifers (for example, see Table 4). 


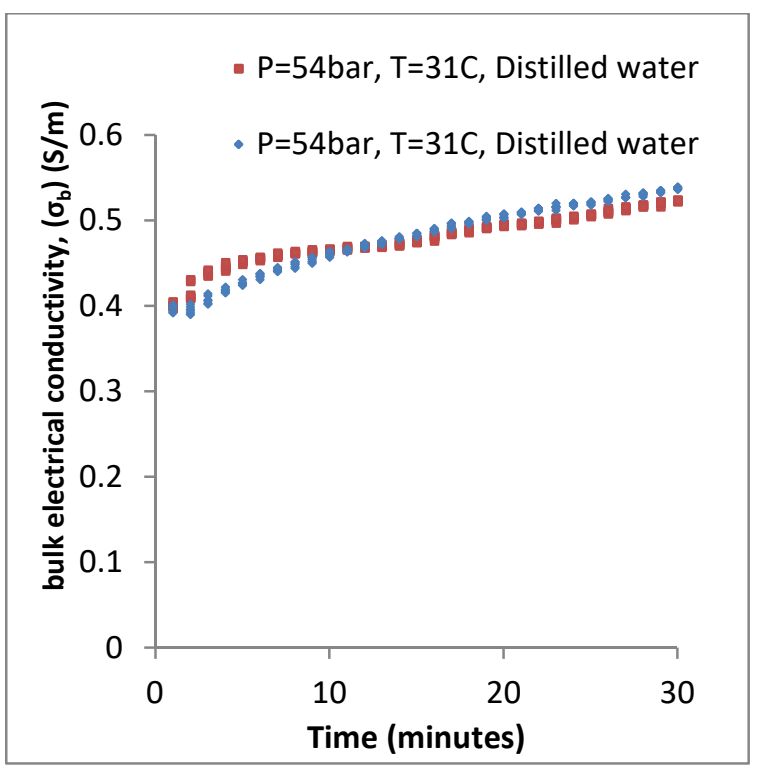

(a)

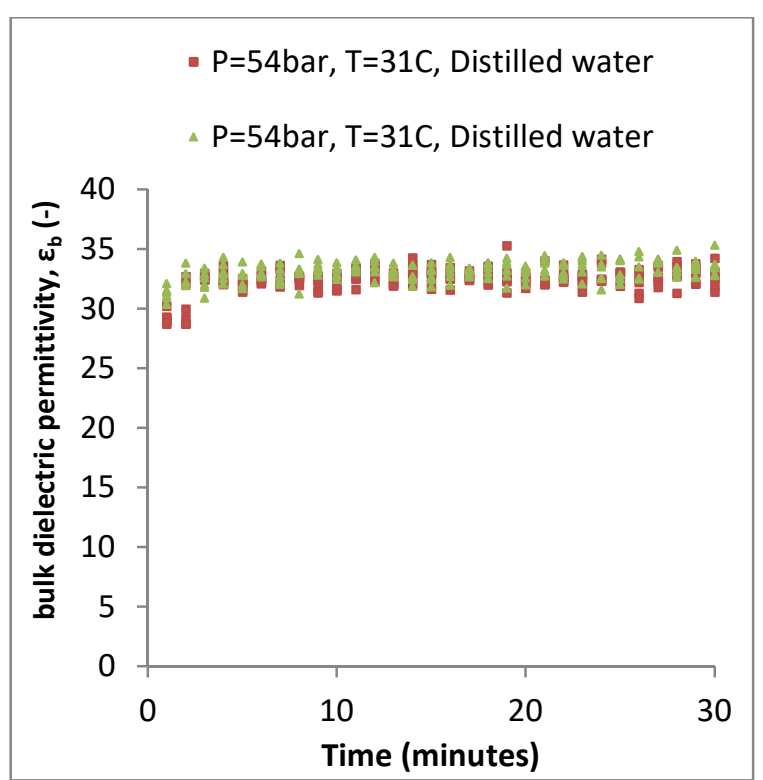

(b)

Figure 4 (a) Repeatability of $\sigma_{b}-t$ and (b) $\varepsilon_{b}-t$ relationships of silica sand saturated by distilled water.

Figure $4(a, b)$ shows the repeatability of $\sigma_{b}-t$ and $\varepsilon_{b}-t$ relationships. The bulk electrical conductivity slightly increased when exposed to $\mathrm{CO}_{2}$, a phenomenon that arises from the dissolution of $\mathrm{CO}_{2}$ in water, as has been well documented in the literature (see, e.g., Abidoye and Das, 2015b; Dethlefsen et al., 2013; Lamert et al., 2012). The increase in the bulk electrical conductivity can be attributed to the increase in the ions, which is caused by the dissolution of $\mathrm{CO}_{2}$ in water. From the reaction engineering point of view, the dissolution behaviour of the $\mathrm{CO}_{2}$ in water results in more acidic fluid conditions in the silica sand- $\mathrm{CO}_{2}$-water system (Equation 2). On the other hand, there is no significant increase in bulk dielectric permittivity in the silica sand- $\mathrm{CO}_{2}$-water system when exposed to $\mathrm{CO}_{2}$.

As depicted in Figure 5a, there is a significant difference in the measurements of $\sigma_{b}$ in the silica sand saturated with distilled water and silica sand saturated with $1 \% \mathrm{w} / \mathrm{w} \mathrm{NaCl}$ brine, both before and after the experiment. A similar trend was observed in the basalt sand saturated with distilled water and brine water as shown in Figure $5 \mathrm{~b}$. The significant difference in bulk electrical conductivity between the porous media saturated with the distilled water and the porous media saturated with the brine water can be connected to the increase in the ions due to an increase in salinity in brine water (Rabiu et al., 2017b; Abidoye and Das, 2015a). The higher trend in the basalt sand can be connected to the presence of high contents of some minerals such as magnesium, iron, and aluminium in the basalt sand, which are very little in silica sand (see Figure A1, A2 in the Appendix). 


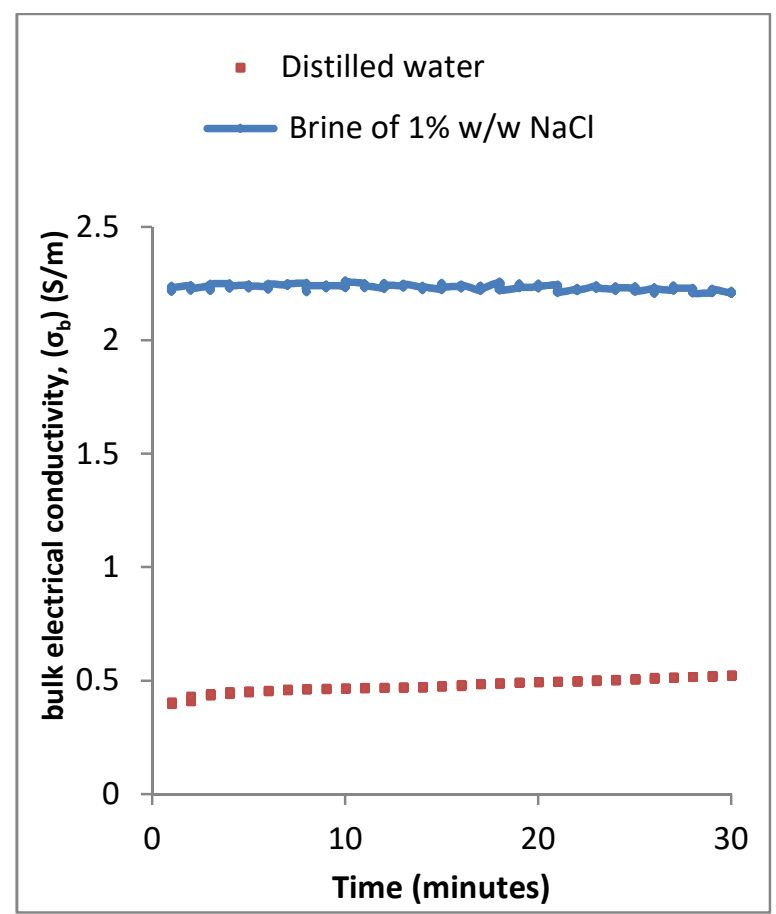

(a)

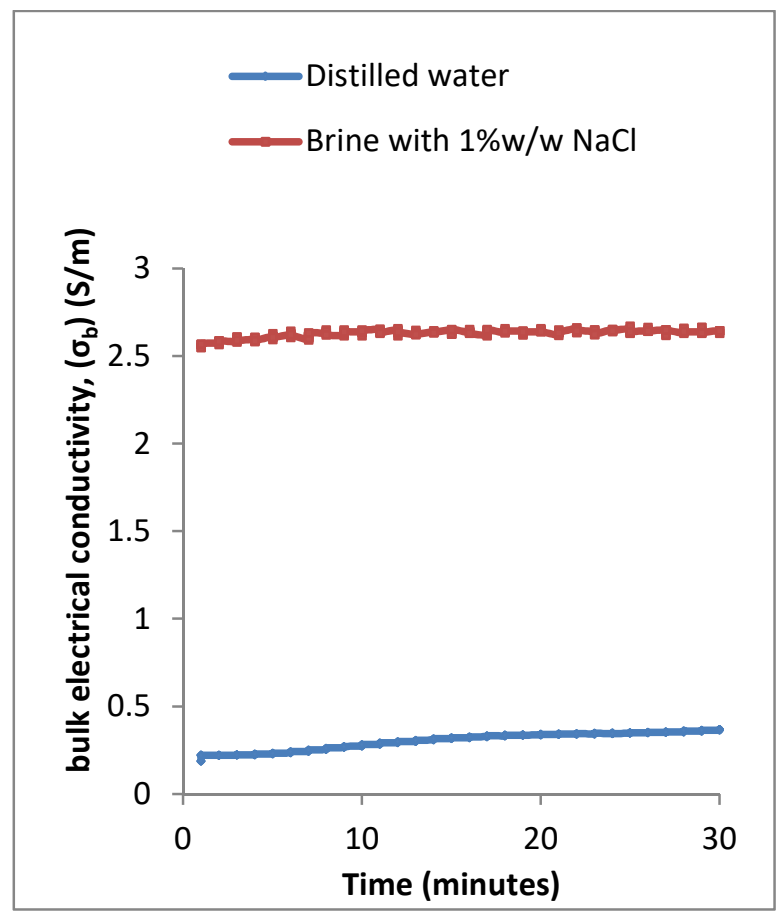

(b)

Figure 5 (a) $\sigma_{b}-t$ relationship in silica sand saturated by distilled water and brine water of $1 \% \mathrm{w} / \mathrm{w}$ $\mathrm{NaCl}(\mathrm{b}) \sigma_{b}-\mathrm{t}$ relationship in basalt sand saturated by distilled water and brine water of $1 \% \mathrm{w} / \mathrm{w} \mathrm{NaCl}$.

Figure $6(a, b)$ represents baseline for $\sigma_{b}$ and $\varepsilon_{b}$ of $\mathrm{CO}_{2}-\mathrm{H}_{2} \mathrm{O}$ without any porous media. As shown in Figure $6(a, b)$, there was a wide gap between $\left(\sigma_{b}-t, \varepsilon_{b}-t\right)$ relationships of $\mathrm{CO}_{2}$ injected into distilled/tap water and $\left(\sigma_{b}-t, \varepsilon_{b}-t\right)$ relationships of $\mathrm{CO}_{2}$ injected into silica sand saturated with distilled/tap/brine (Figure $7 a, b)$, and this can be attributed to the presence of porous media.

Moreover, this study focuses on understanding the potential impacts of water quality on the sand/water/ $/ \mathrm{CO}_{2}$ system, chosen on the basis of different qualities of groundwater reported in the literature (Table 4). $\mathrm{CO}_{2}$ injection into three different potable groundwater types with the same pressure and temperature conditions in the laboratory scale have been carried out to assess the impact of groundwater types on the dielectric properties during the monitoring process in silica/basalt sand-water- $\mathrm{CO}_{2}$ systems.

The bulk electrical conductivity and bulk dielectric permittivity of the silica sand saturated by distilled, tap and brine water were measured and shown in Figure $7(a, b)$. For the silica sand saturated by either distilled or tap water, the baseline of the bulk electrical conductivity $\left(\sigma_{\mathrm{b}}\right)$ before their exposure to $\mathrm{CO}_{2}$ measured an average value of $0.2 \mathrm{~S} / \mathrm{m}( \pm 0.1 \mathrm{~S} / \mathrm{m}$ standard deviation $)$.

Table 4 Different fluids that resemble several possible groundwater aquifers

\begin{tabular}{|l|l|l|l|l|}
\hline & Fluid 1 & Fluid 2 & Fluid 3 & Fluid 4 \\
\hline pH & 6.73 & 7.44 & 6.95 & 7.04 \\
\hline $\begin{array}{l}\text { Fluid } \\
\text { component }\end{array}$ & Distilled water & $\begin{array}{l}\text { Tap water (consists of } \\
\left.\mathrm{Ca}^{2+}, \mathrm{Mg}^{2+}, \mathrm{K}^{+}\right)\end{array}$ & $\begin{array}{l}\text { Distilled water + } \\
0.3 \% \mathrm{w} / \mathrm{w} \mathrm{NaCl}\end{array}$ & $\begin{array}{l}\text { Distilled water + } \\
0.3 \% \mathrm{w} / \mathrm{w} \mathrm{MgCl}\end{array}$ \\
\hline $\begin{array}{l}\text { Potable aquifer } \\
\text { condition }\end{array}$ & $\begin{array}{l}\text { Neutral aquifer } \\
\text { (Borner et al. } \\
\text { 2013) }\end{array}$ & $\begin{array}{l}\text { Average aquifer that is } \\
\text { not polluted (Borner et } \\
\text { al. 2013) }\end{array}$ & $\begin{array}{l}\text { Aquifer } \\
\text { contain moderate } \\
\text { NaCl salt }\end{array}$ & $\begin{array}{l}\text { Aquifer } \\
\text { contain moderate } \\
\text { MgCl salt }\end{array}$ \\
\hline
\end{tabular}




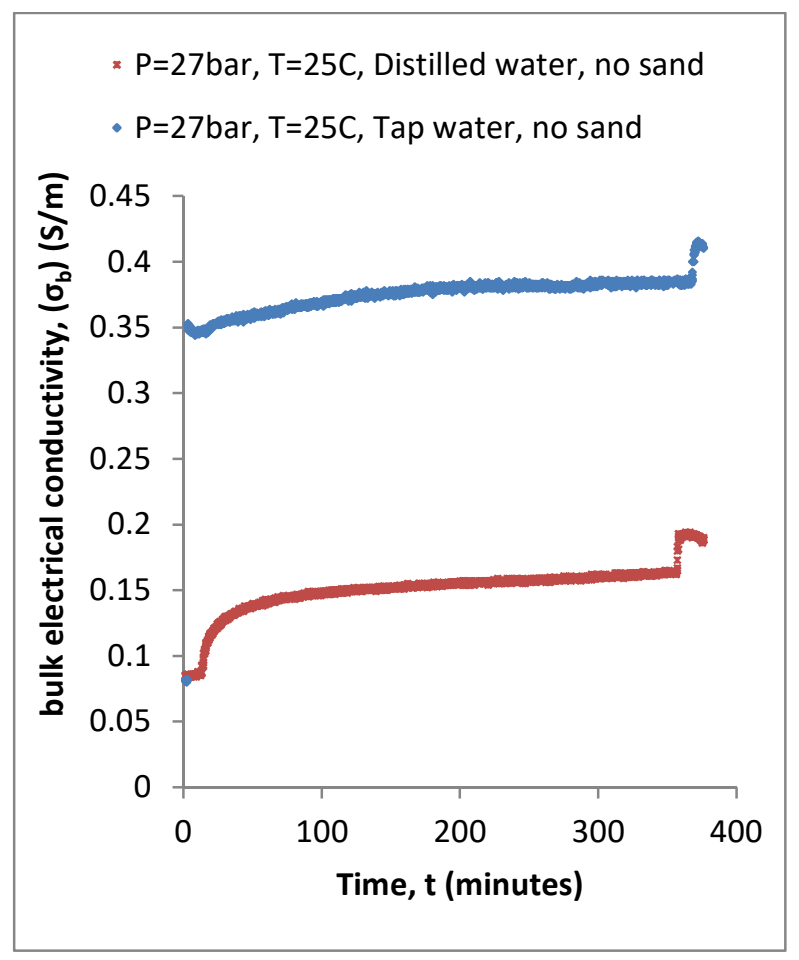

347 baseline of $\sigma_{b}$ and $\varepsilon_{b}$ for $\mathrm{CO}_{2}-\mathrm{H}_{2} \mathrm{O}$ system.

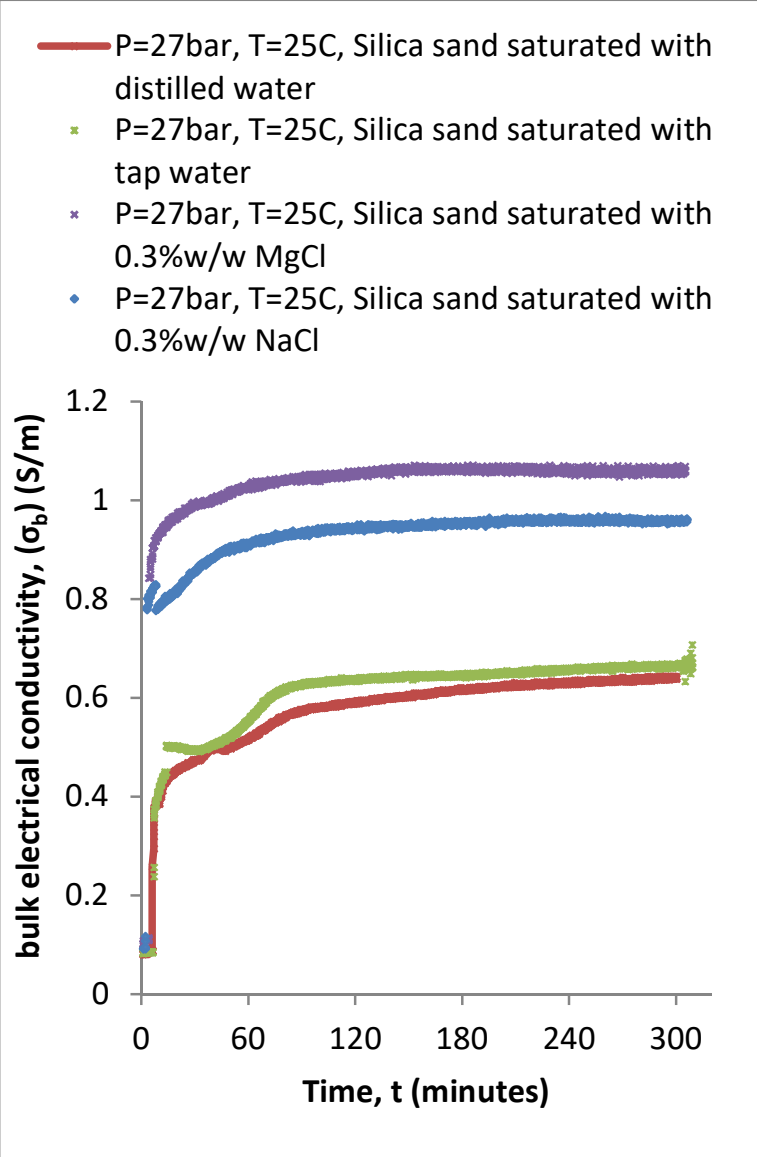

(a)

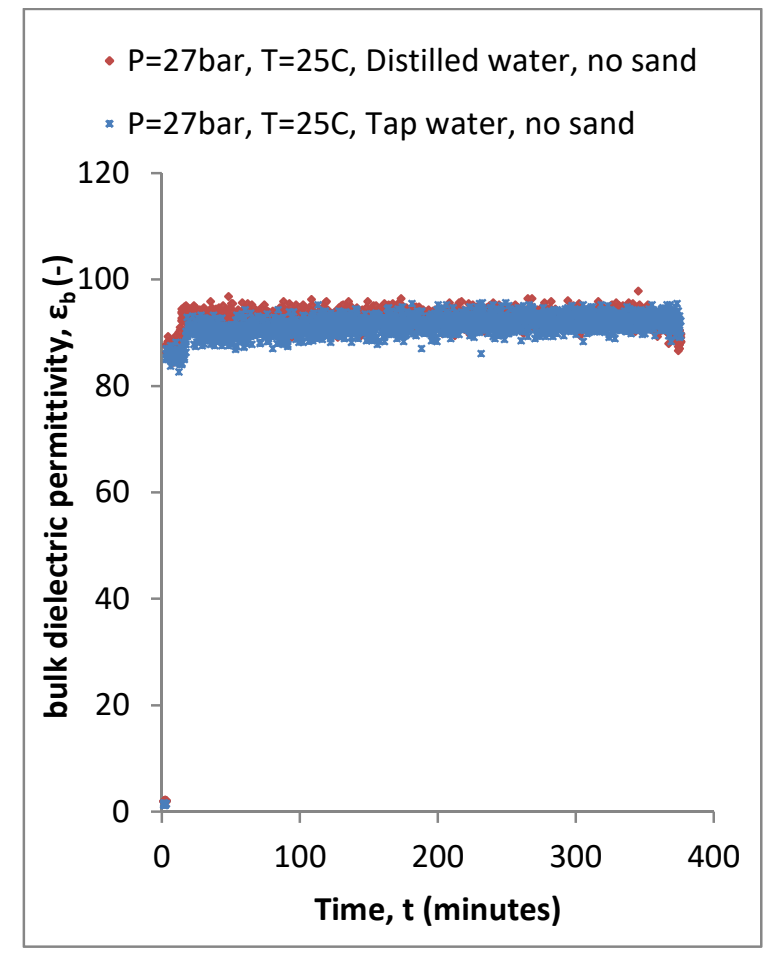

(a)

(b)

Figure 6 (a) $\sigma_{b}-t$ and (b) $\varepsilon_{b}-t$ relationships of $\mathrm{CO}_{2}$ injected into distilled/tap water; it represents

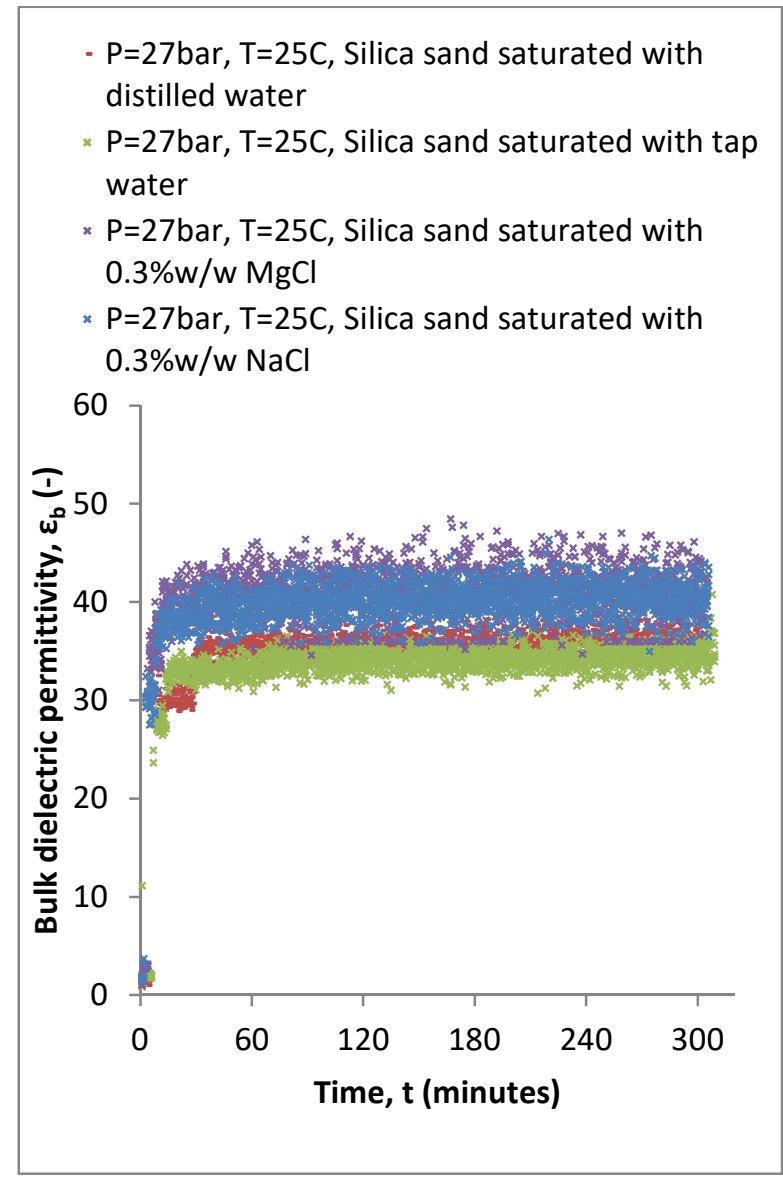

(b)

Figure 7 (a) $\sigma_{b}-t$ and (b) $\varepsilon_{b}-t$ relationships of $\mathrm{CO}_{2}$ injected into silica sand saturated with distilled/tap/brine $(\mathrm{MgCl}$ and $\mathrm{NaCl})$ water. 
After 5 hours of $\mathrm{CO}_{2}$ dissolution in the water, the average bulk electrical conductivity $\left(\sigma_{\mathrm{b}}\right)$ had increased to $0.6 \pm 0.10 \mathrm{~S} / \mathrm{m}$ (Figure 7a). The same trend was observed for the silica sand saturated with both $\mathrm{MgCl}$ and $\mathrm{NaCl}$ brine, i.e., their bulk electrical conductivity increased after the addition of $\mathrm{CO}_{2}$ and this can be linked to the increase in ions due to the dissolution of $\mathrm{CO}_{2}$ in water. This was also observed in the work of Abidoye and Das (2015b), but their work was limited to distilled water. Also, Dethlefsen et al. (2013) as well as Lamert et al. (2012) observed similar trends during the monitoring of $\mathrm{CO}_{2}$ injection in field experiments. On the other hand, the present work uses a laboratory experiment to study the monitoring of $\mathrm{CO}_{2}$ leakage into different types of water that can be found in groundwater aquifers. The undertaken assessment is generally representative of potable groundwater contaminated by $\mathrm{CO}_{2}$. Also, as shown in Figure $7 \mathrm{~b}$, the dielectric permittivity of tap water and distilled water are very similar, i.e., both increased to $36 \pm 6$ after 5 hours of $\mathrm{CO}_{2}$ dissolution in the water, but the silica sand saturated with both $\mathrm{MgCl}$ and $\mathrm{NaCl}$ brine have higher dielectric permittivity and the difference may be attributed to effect of more ions in the saline aquifers.

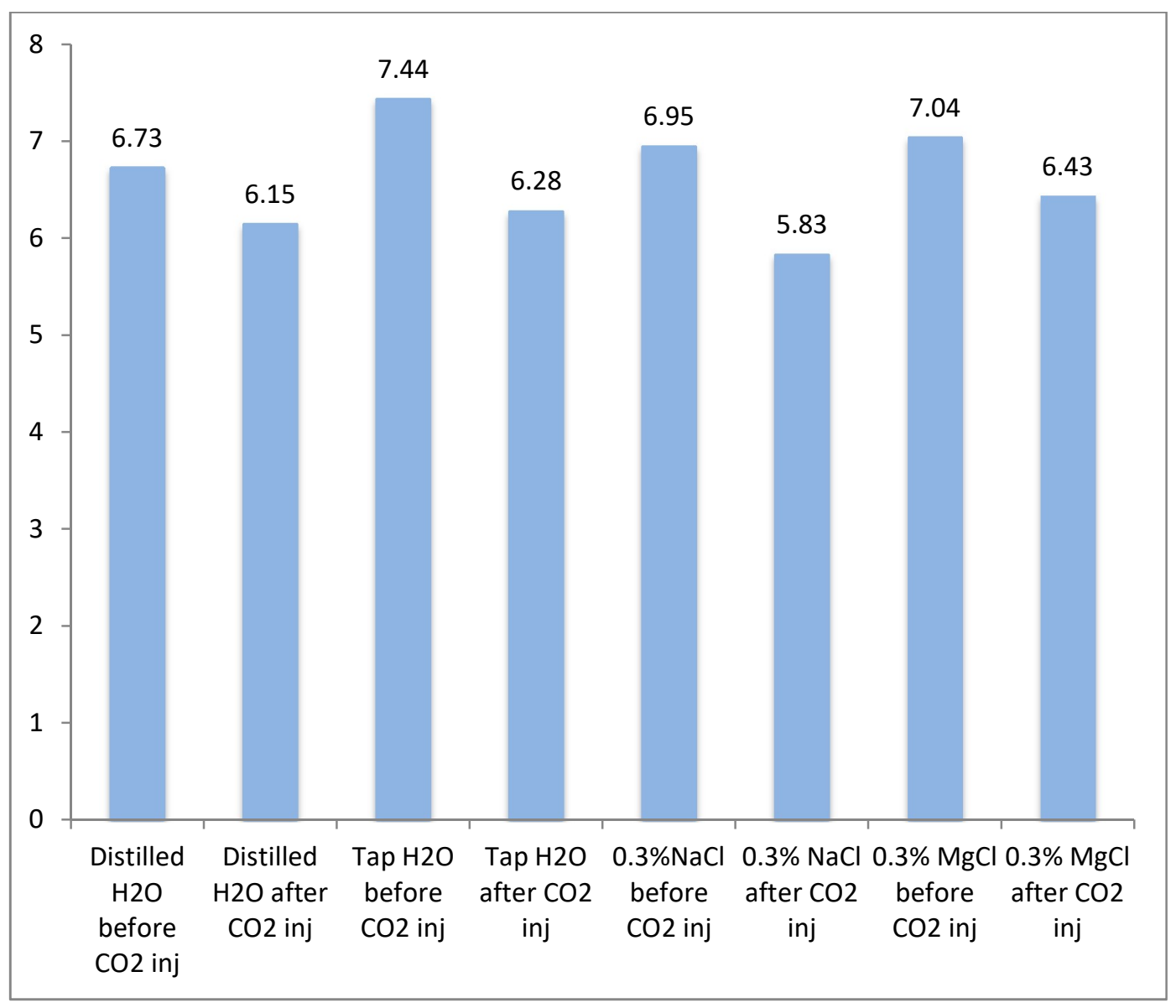

Figure $8 \mathrm{pH}$ of silica sand saturated with water $\left(\mathrm{H}_{2} \mathrm{O}\right)$ before and after $\mathrm{CO}_{2}$ injection (inj)

In addition, Figure 8 shows that $\mathrm{pH}$ decreased after injection of $\mathrm{CO}_{2}$ into distilled, tap, $0.3 \% \mathrm{w} / \mathrm{w} \mathrm{NaCl}$ and $0.3 \% \mathrm{w} / \mathrm{w} \mathrm{MgCl}$ brine water, respectively. Noticeably, the initial $\mathrm{pH}$ in the tap water has the highest in comparison with the other types of water solutions used in the experiment; and this can be attributed to the different constituents that were contained in the tap water which were absent in other water solutions. This is observed in the work of Petit et al. (2020) but their work was limited to only water, water and sand or water and limestone; and they concluded that $\mathrm{pH}$ measurements seem to be tremendous indicators for monitoring a gas plume during $\mathrm{CO}_{2}$ geological storage. Furthermore, as clearly illustrated in Figure 8; the sodium chloride brine solution after exposure to $\mathrm{CO}_{2}$ has the lowest $\mathrm{pH}$. This is followed by the distilled water solution, the tap water solution and the $\mathrm{MgCl}$ brine solution, respectively. Hence, the highest acidity was found in the sodium chloride brine solution after $\mathrm{CO}_{2}$ exposure while the lowest acidity was observed in the magnesium chloride brine solution. 
The work presented in this paper attempts to identify the key physico-chemical and dielectric characteristics of basalt and silica sites contaminated by $\mathrm{CO}_{2}$ due to a CCS project. In addressing this aim, the bulk electrical conductivity $\left(\sigma_{\mathrm{b}}\right)$ and bulk dielectric permittivity $\left(\varepsilon_{\mathrm{b}}\right)$ of basalt and silica samples were measured simultaneously using the time domain reflectometry (TDR) technique while the $\mathrm{pH}$ meter/probe was used to measure the $\mathrm{pH}$ of the water sample collected before and after the static flow experiment. After exposure to $\mathrm{CO}_{2}$, the decrease in $\mathrm{pH}$ was clearly observed in both basalt and silica sand samples. The decrease in $\mathrm{pH}$ is was attributed to the dissolution of the $\mathrm{CO}_{2}$ in the water which changed the solution into carbonic acid. On the other hand, the bulk dielectric permittivity increased as $\mathrm{CO}_{2}$ started to be injected. Contrarily, the bulk electrical conductivity shows no changes after $\mathrm{CO}_{2}$ injection started but increased after a while. This can be attributed to the dissolution of $\mathrm{CO}_{2}$ in water, since it takes some time before the dissolution occurs. Therefore, the bulk electrical conductivity, bulk dielectric permittivity and $\mathrm{pH}$ can be used as in a multi-parameter tool to monitor the $\mathrm{CO}_{2}$ leakage into the potable groundwater. With CCS still being explored mostly in a few developed countries in the world, these monitoring techniques could be of real practical use in the future. It is therefore anticipated that the developed system can be developed further in future work, e.g., as Internet of Things (IOT) system for continuous monitoring of CCS sites. It should also be stated that more detailed experiments on the flow behaviour (e.g., dynamic flow of $\mathrm{CO}_{2} /$ water in the porous samples) and the related effects on the physico-chemical and dielectric parameters of basalt and silica media should be carried out in the future. Statistical analysis of the data generated using nonlinear regression may be carried out too to analyse the significance of the correlation among different parameters. In addition, machine learning tools such as those reported by Song et al. (2020) may be explored for analysis of the data generated by the monitoring tools at a site.

\section{References}

Abidoye, L.K., Das, D.B., 2015a. Geoelectrical characterization of carbonate and silicate porous media in the presence of supercritical $\mathrm{CO}_{2}$-water flow. Geophysical Journal International, 203(1), pp.79-91. https://doi.org/10.1093/gji/ggv283.

Abidoye, L.K., Das, D.B., 2015b. pH, geoelectrical and membrane flux parameters for the monitoring of water-saturated silicate and carbonate porous media contaminated by $\mathrm{CO}_{2}$. Chemical Engineering Journal, 262, pp.1208-1217. https://doi.org/10.1016/j.cej.2014.10.036.

Abidoye, L.K., Das, D.B., 2020. Impacts of dynamic capillary pressure effects in supercritical $\mathrm{CO}_{2}-$ Water flow: Experiments and numerical simulations. Advances in Water Resources, 136, DOI: 10.1016/j.advwatres.2020.103504.

Adebayo, A.R., Kandil, M.E., Okasha, T.M., Sanni, M.L., 2017. Measurements of electrical resistivity, NMR pore size and distribution, and x-ray CT-scan for performance evaluation of $\mathrm{CO}_{2}$ injection in carbonate rocks: A pilot study. International Journal of Greenhouse Gas Control,63, pp. 1-11. DOI: 10.1016/j.jgggc.2017.04.016.

Ajayi, T., Gomes, J.S., Bera, A., 2019. A review of $\mathrm{CO}_{2}$ storage in geological formations emphasizing modeling, monitoring and capacity estimation approaches. Pet. Sci. 16, 1028-1063. https://doi.org/10.1007/s12182-019-0340-8.

Al-Khdheeawi, E. A., Vialle, S., Barifcani, A., Sarmadivaleh, M., Zhang, Y. and Iglauer, S., 2017. Impact of salinity on $\mathrm{CO}_{2}$ containment security in highly heterogeneous reservoirs. Greenhouse Gas Sci Technol. 8(1), pp. 93-105. doi:10.1002/ghg.1723.

Altman, S.J., Aminzadeh, B., Balhoff, M.T., Bennett, P.C., Bryant, S.L., Cardenas, M.B., Chaudhary, K., Cygan, R.T., Deng, W., Dewers, T., DiCarlo, D.A., Eichhubl, P., Hesse, M.A., Huh, C., Matteo, E.N., Mehmani, Y., Tenney, C.M., Yoon, H., 2014. Chemical and Hydrodynamic Mechanisms for 
Archie G., 1942. The electrical resistivity log as an aid in determining some reservoir characteristics.

Transaction of the American Institute of Mining and Metallurgical Engineers, 146, pp. 54-61. https://personal.ems.psu.edu/ radovic/EME590_Archie_1942.pdf.

Blackford, J., Alendal, G., Avlesen, H., Brereton, A., Cazenave, P. W., Chen, B., Phelps, J., 2020. Impact and detectability of hypothetical CCS offshore seep scenarios as an aid to storage assurance and risk assessment. International Journal of Greenhouse Gas Control, 95, 102949. doi:10.1016/j.jjggc.2019.102949.

Borner, J.H., Herdegen, V., Repke, J., Spitzer, K., 2013. The impact of $\mathrm{CO}_{2}$ on the electrical properties of water bearing porous media - laboratory experiments with respect to carbon capture and storage. Geophysical Prospecting, 61 (1), 446-460. doi: 10.1111/j.1365-2478.2012.01129.x.

Borner, J.H., Herdegen, V., Repke, J.U., Spitzer, K., 2017. Special induced polarization of the threephase system CO2-brine-sand under reservoir conditions, Geophysical Journal International, 208 (1), pp. 289-305. DOI: 10.1093/gji/ggw389.

Borner, J.H., Spitzer, K., 2019. Monitoring of $\mathrm{CO}_{2}$ sequestration and leakage using borehole transient electromagnetics and the DC resistivity method: a 3D feasibility study incorporating realistic geological scenarios. Society of Exploration Geophysicists International Exposition and 83rd Annual Meeting, SEG 2013:Expanding Geophysical Frontiers, pp. 4461-4465, doi: 10.1190/segam20130566.1.

Bosch, D., Ledo, J., Queralt, P., Bellmunt, F., Luquot, L., Gouze, P., 2016. Core-scale electrical resistivity tomography (ERT) monitoring of $\mathrm{CO}_{2}$-brine mixture in Fontainebleau sandstone. Journal of Applied Geophysics, 130, pp. 23-36, DOI: 10.1016/j.jappgeo.2016.03.039.

Cao, C., Liu, H., Hou, Z., Mehmood, F., Liao, J., Feng, W., 2020. A Review of $\mathrm{CO}_{2}$ Storage in View of Safety and Cost-Effectiveness. Energies, 13(3), pp. 1-45. doi:10.3390/en13030600.

Dafflon, B., Wu, Y., Hubbard, S.S., Birkholzer, J.T., Daley, T.M., Pugh, J.D., Peterson, J.E., Trautz, R.C., 2012. Monitoring $\mathrm{CO}_{2}$ intrusion and associated geochemical transformations in a shallow groundwater system using complex electrical methods. Environmental Science and Technology, 47(1), pp.314-321. dx.doi.org/10.1021/es301260e.

Dethlefsen, F., Kober, R., Schafer, D., Hagrey, S.A.A., Hornbruch, G., Ebert, M., Dahmke, A., 2013. Monitoring Approaches for Detecting and Evaluating $\mathrm{CO}_{2}$ and Formation Water Leakages into Nearsurface Aquifers. Energy Procedia, 37, pp. 4886-4893.

https://doi.org/10.1016/j.egypro.2013.06.399.

Emami-Meybodi, H., Hassanzadeh, H., Green, C., Ennis-King, J., 2015. Convective dissolution of $\mathrm{CO}_{2}$ in saline aquifers: Progress in modeling and experiments, International Journal of Greenhouse Gas Control, 40, pp. 238-266, DOI: 10.1016/j.ijggc.2015.04.003.

Erfani, H., Babaei, M., Niasar, V., 2020. Signature of Geochemistry on Density-Driven $\mathrm{CO}_{2}$ Mixing in Sandstone Aquifers. Water Resources Research, 56 (3), DOI:10.1029/2019WR026060.

Falcon-Suarez, I., Marín-Moreno, H., Browning, F., Lichtschlag, A., Robert, K., North, L.J., Best, A.I., 2017. Experimental assessment of pore fluid distribution and geomechanical changes in saline sandstone reservoirs during and after $\mathrm{CO}_{2}$ injection, International Journal of Greenhouse Gas Control, 63, pp. 356-369. DOI: 10.1016/j.jjggc.2017.06.019.

Furre, A., Eiken, O., Alnes, H., Vevatne, J. N., Kaer, A. F., 2017. 20 years of monitoring $\mathrm{CO}_{2}$-injection at Sleipner, 13th International Conference on Greenhouse Gas Control Technologies, GHGT-13, 14- 
18 November 2016, Lausanne, Switzerland, Energy Procedia, 114, pp. 3916 - 3926, doi: 10.1016/j.egypro.2017.03.1523.

Gupta, P.K., Yadav, B. (2020). Leakage of $\mathrm{CO}_{2}$ from geological storage and its impacts on fresh soilwater systems: a review. Environmental Science and Pollution Research, 27 (12), pp. 12995-13018, DOI: $10.1007 / \mathrm{s} 11356-020-08203-7$

Holloway, S., 2007. Carbon dioxide capture and geological storage. Phil Trans. R. Soc. A, 365, pp.1095-1107. doi:10.1098/rsta.2006.1953.

Jin, Y., Li, S., Yang, D., 2020. Experimental and theoretical quantification of the relationship between electrical resistivity and hydrate saturation in porous media, Fuel, 269, DOI: 10.1016/j.fuel.2020.117378.

Kampman, N., Bickle, M., Wigley, M., Dubacq, B., 2014. Fluid flow and $\mathrm{CO}_{2}$-fluid-mineral interactions during $\mathrm{CO}_{2}$-storage in sedimentary basins. Chemical Geology, 369, pp. 22-50, DOI: 10.1016/j.chemgeo.2013.11.012.

Kharaka, Y.K., Thordsen, J.J., Kakouros, E., Ambats, G., Herkelrath, W.N., Beers, S.R., Birkholzer, J.T., Apps, J.A., Spycher, N.F., Zheng, L., Trautz, R.C., Rauch, H.W., Gullickson, K.S., 2010. Changes in the chemistry of shallow groundwater related to the 2008 injection of $\mathrm{CO}_{2}$ at the ZERT field site, Bozeman, Montana. Environ Earth Sci, 60(2), pp.273-284.

https://doi.org/10.1007/s12665-009-0401-1.

Khudaida, K., Das, D.B., 2014. A numerical study of capillary pressure-saturation relationship for supercritical carbon dioxide $\left(\mathrm{CO}_{2}\right)$ injection in deep saline aquifer. Chemical Engineering Research and Design, 92(12), pp.3017-3030. https://doi.org/10.1016/j.cherd.2014.04.020.

Kim, C. Y., Han, W. S., Park, E., Jeong, J., Xu, T., 2018. $\mathrm{CO}_{2}$ Leakage-Induced Contamination in Shallow Potable Aquifer and Associated Health Risk Assessment. Geofluids, vol. 2018, pp. 119. doi:10.1155/2018/4834601.

Kumar, R., Campbell, S., Sonnenthal, E., Cunningham, J., 2020. Effect of brine salinity on the geological sequestration of $\mathrm{CO}_{2}$ in a deep saline carbonate formation. Greenhouse Gases: Science and Technology. 10(2), 296-312. doi:10.1002/ghg.1960.

Lamert, H., Geistlinger, H., Werban, U., Schutze, C., Peter, A., Hornbruch, G., Schulz, A., Pohlert, M., Kalia, S., Beyer, M., Grobmann, J., Dahmke, A., Dietrich, P., 2012. Feasibility of geoelectrical monitoring and multiphase modeling for process understanding of gaseous $\mathrm{CO}_{2}$ injection into a shallow aquifer. Environmental Earth Sciences, 67(2), pp.447-462.

Little, M.G., Jackson, R.B., 2010. Potential Impacts of Leakage from Deep $\mathrm{CO}_{2}$ Geosequestration on Overlying Freshwater Aquifers, Environ. Sci. Technol. 44 (23), 9225-9232. DOI: 10.1021/es102235w.

Metz, B., Davidson, O., Coninck, H., Loos, M., Meyer, L., 2005. IPCC special report on carbon dioxide capture and storage, Intergovernmental Panel on Climate Change, Geneva (Switzerland). Working Group III. Cambridge University Press. https://www.ipcc.ch/pdf/specialreports/srccs/srccs_wholereport.pdf [Accessed 31 October 2017].

Myer, L., 2011.Global Status of Geologic $\mathrm{CO}_{2}$ Storage Technology Development, A report from the U.S. Carbon Sequestration Council,http://www.iea-coal.org.uk/documents/82579/7892/Global-statusof-geologic-CO2-storage-technology-development [Accessed 02 November 2016].

Petit, A., Cerepi, A., Loisy, C., Le Roux, O., Rossi, L., Chiquet, P., Estublier, A, Gance, J., Garcia, B., Gauchet, L., Hautefeuille, B., Lavielle, B., Van Lang, L., Noirez, S, Texier, B., Bachaud, P., Bouquet, S., 2020. Aquifer- $\mathrm{CO}_{2}$ Leak project: Physicochemical characterization of the $\mathrm{CO}_{2}$ leakage impact on a carbonate shallow freshwater aquifer, EGU General Assembly 2020, doi: 10.5194/egusphereegu2020-13889. 
Petrik, C., Mabee, S.B., 2011. Experimental summarizing the potential of $\mathrm{CO}_{2}$ sequestration in the basalts of Massachusetts-Final report prepared for Massachusetts Clean Energy Center,Boston.http://www.geo.umass.edu/stategeologist/Products/reports/BasaltSequestrationReport. pdf. [Accessed 25 July 2016].

Rabiu, K.O., Han, L., Das, D.B., 2017a. $\mathrm{CO}_{2}$ Trapping in the Context of Geological Carbon Sequestration, In: Abraham, M.A. (Ed.), Encyclopedia of Sustainable Technologies. Elsevier, pp. 461475, DOI:10.1016/B978-0-12-409548-9.10124-1.

Rabiu, K.O., Abidoye, L.K., Das, D.B., 2017b. Geo-Electrical Characterisation for $\mathrm{CO}_{2}$ Sequestration in Porous Media. Environ. Process, 4(2), pp. 303-317, doi:10.1007/S40710017-0222-2.

Snaebjornsdottir, S.O., Sigfusson, B., Marieni, C., Goldberg, D., Gislason, S.R., Oelkers, E.H., 2020. Carbon dioxide storage through mineral carbonation, Nature reviews, Earth and Environment, 1, pp. 90-102, doi:10.1038/s43017-019-0011-8.

Song, Y., Sung, W., Jang, Y., Jung, W., 2020. Application of an artificial neural network in predicting the effectiveness of trapping mechanisms on $\mathrm{CO}_{2}$ sequestration in saline aquifers, International Journal of Greenhouse Gas Control, 98, doi: 10.1016/j.ijggc.2020.103042.

Suekane, T., Furukawa, N., Tsushima, S., Hirai, S., Kiyota, M., 2009. Application of MRI in the Measurement of Two-Phase Flow of Supercritical $\mathrm{CO}_{2}$ and Water in Porous Rocks. Journal of Porous Media, 12 (2), pp. 143-154, DOI: 10.1615/JPorMedia.v12.i2.40.

Szulczewski, M.L., 2013. The Subsurface Fluid Mechanics of Geologic Carbon Dioxide Storage. (PhD Thesis) Massachusetts Institute of Technology, USA.

https://sequestration.mit.edu/pdf/2013_MikeSzulczewski_MIT-PhD_thesis.pdf [Accessed 25 July 2019].

Talapatra, A. A., 2020. Study on the carbon dioxide injection into coal seam aiming at enhancing coal bed methane (ECBM) recovery. J Petrol Explor Prod Technol, 10, pp. 1965-1981. https://doi.org/10.1007/s13202-020-00847-y.

Terzi, K., Aggelopoulos, C.A., Bountas, I., Tsakiroglou, C.D., 2014. Effects of carbon dioxide on the mobilization of metals from aquifers. Environ. Sci. Technol, 48, pp. 4386-4394. http://www.peacesoftware.de/einigewerte/co2_e.html [Accessed 23 September 2016].

Wan, L., Han, M., Aljanobi, H., Zhdanov, M. 2018. Feasibility study of gravity gradiometry monitoring of $\mathrm{CO} 2$ sequestration in deep reservoirs using surface and borehole data, SEG Technical Program Expanded Abstract, doi: 10.1190/segam2018-2996382.1.

White, S., Carroll, S., Chu, S., Bacon, D., Pawar, R., Cumming, L., Hawkins, J., Kelley, M., Demirkanli, I., Middleton, R., Sminchak, J., Pasumarti, A (2020). A risk-based approach to evaluating the Area of Review and leakage risks at $\mathrm{CO} 2$ storage sites. International Journal of Greenhouse Gas Control, 93, art. no. 102884. DOI: 10.1016/j.jjggc.2019.102884.

Yang, X., Buscheck, T.A., Mansoor, K., Wang, Z., Gao, K., Huang, L., Appriou, D., Carroll, S.A. (2019). Assessment of geophysical monitoring methods for detection of brine and CO2 leakage in drinking water aquifers. International Journal of Greenhouse Gas Control, 90, art. no. 102803, DOI: $10.1016 / j . j$.jggc.2019.102803. 


\section{MicroXRF Analysis Report}

Preparedfor: CompanyName Here

Prepased by:

Your Name Here

\section{EDAX ${ }^{\text {TSE }}$}

AMETEX

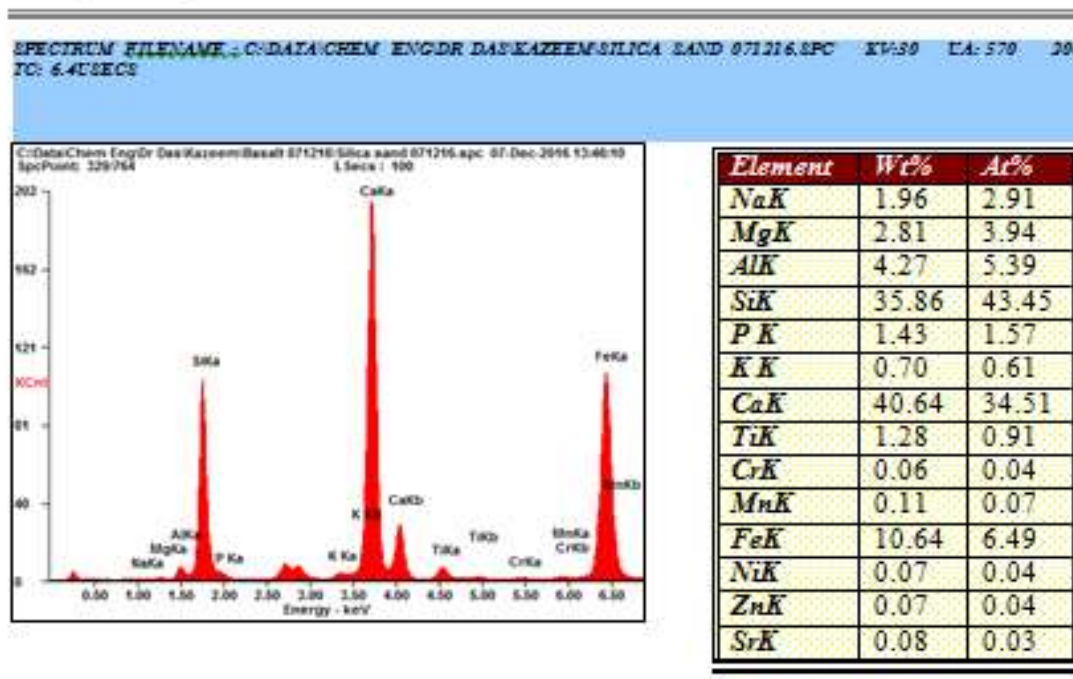

$07 / 12 / 2016$

DOS EN-SPOT 


\section{MicroXRF Analysis Report}

Preparedfor: Company Name Here

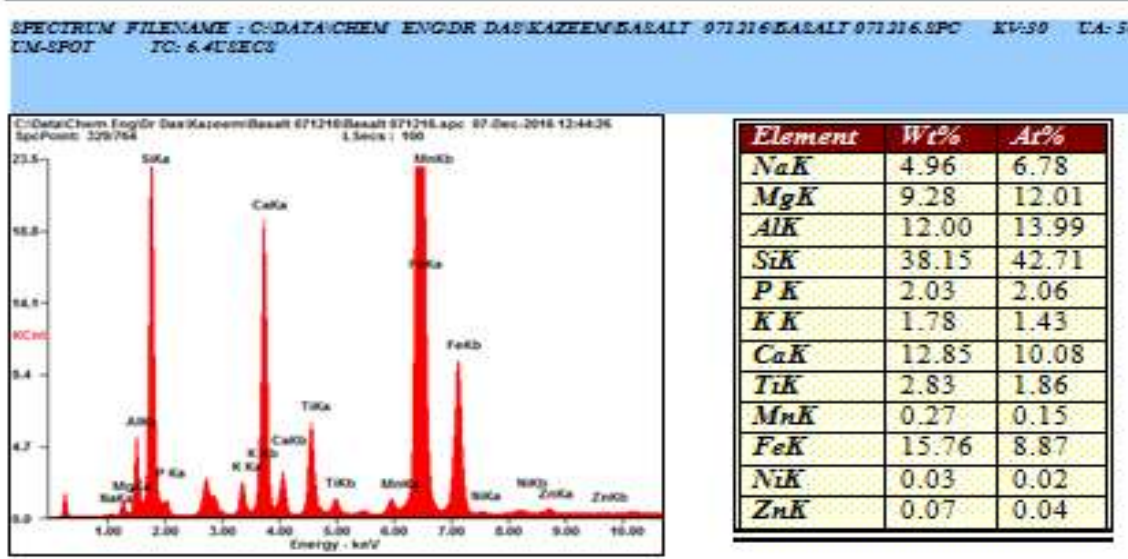

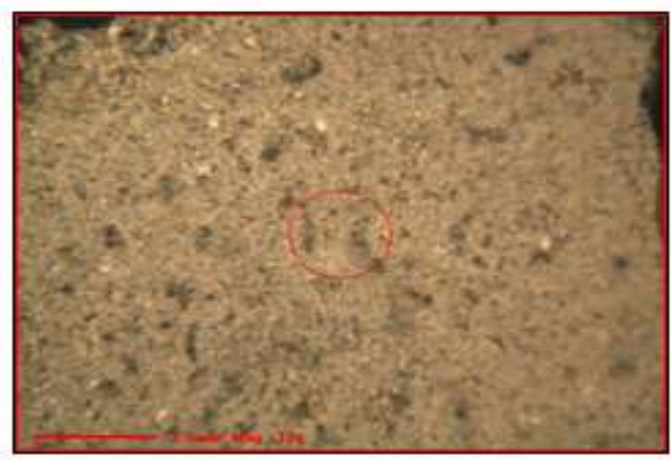

Figure A2 X-Ray Fluorescence (XRF) mineral analysis for Basalt sand particles. 